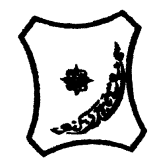

Bayero Journal of Pure and Applied Sciences, 13(2): 87 - 93

Received: May, 2020

Accepted: Septembder, 2020

ISSN $2006-6996$

\title{
RELATIONSHIP BETWEEN SECOND TO FOURTH DIGIT RATIO (2D:4D) AND ACADEMIC PERFORMANCE AMONG STUDENTS IN NIGERIA.
}

\author{
Anas, Y.I. ${ }^{1}$ and Badamasi, M.I. ${ }^{1 *}$ \\ Department of Anatomy, Faculty of Basic Medical Sciences, College of Health Sciences, Bayero \\ University Kano. \\ *Corresponding author: badamasiibrahimmohammed@gmail.com
}

\begin{abstract}
The second to fourth digit ratio (2D:4D), is a sexually dimorphic trait, with males on the average having lower ratios than females 2D:4D. It had been correlated with several psychosocial features. The present study is primarily aimed at investigating the existence of the association between digit ratio (2D:4D) with academic performance of 205 secondary school students (110 males and 95 females) in Kano State, Nigeria. Academic performance of the students was measured from the terminal examinations results in three key subjects (Maths, English and Biology) and these results were obtained from the schools managements. A significantly low 2D:4D (a correlate of high prenatal testosterone and low prenatal oestrogen) was observed in male students compared to females and the differences in digit size measurments between male and female students were also statistically significant $(P<0.05)$. Female students performed significant/y better in all the 3 subjects, but there was no correlation between the performance and any of the 3 subjects or their cumulative average with 2D:4D ratio of the right or left hand in the current study. However, a positive but negative correlation between the sizes of the left and right digits, with academic performance in all subjects in males and two subjects (English and Biology) in females were observed. It is therefore sufficient to conclude that 2D:4D ratio was not associated with better performance in the current study.
\end{abstract}

Key words: Anthopometry, Academic performance, undergraduate-students, Gender, Digit ratio

\section{INTRODUCTION}

It has been consistently reported from $19^{\text {th }}$ century to date that men's 2D:4D ratios were averagely lower than those for females and this sexual dimorphism is well established by the 13th week of in utero life and remains so in all stages of the human development (Tektas et al., 2019; Trivers et al., 2006; Malas et al., 2005; McIntyre et al., 2005; Csatho et al. 2003a; Manning et al., 1998; Williams et al., 2003). The sexual dimorphism for the 2D:4D has been reported across ethnic groups and different primates and mammals (Burley and Foster 2004; Brown et al., 2002).

A number of studies had suggested that the digit ratio was positively associated with prenatal estrogen and negatively associated with prenatal testosterone (Manning, 2002; Danborno et al., 2007 and Breedlove, 2010). Specifically, it has been reported that the size of index finger (digit 2 ) is an indicator of prenatal estrogen levels while the length of the ring finger (digit 4) appears to 2 be determined by prenatal testosterone levels (Manning, 2002).

There are few studies in the literature that assessed for correlation between either the size of the fourth digit or second digit independently, with traits such as homosexuality and physical aggression (Manning, 2002; Robinson and Manning, 2000). There are numerous studies in the literature regarding the association between hand digit ratio and traits such as body height, body mass index, adult weight and birth weight (Danborno et al., 2010, Klimek et al., 2014). Thus, the more associations reported with the digit ratio compared to the dimensions of the digit alone strongly suggest that neither of the underlying hormones that influence the digit sizes is solely involved in the regulation of complex psychosocial triats (Zheng and Cohn, 2011; Mrazik and Dombrowski, 2010). A gender specific prediction of 2D:4D for psychological traits had also been reported. 
BAJOPAS Volume 13 Number 2, December, 2020 Aggression, atheletism, masculinity, music talent were common among men with low 2D:4D ratio (Rammsayer and Troche, 2007; Hönekopp et al., 2006; Luxen and Buunk, 2005; Bailey and Hurd, 2005; Pokrywka et al., 2005; Rahman and Wilson, 2003; Csathó et al., 2003a; Manning et al., 2000). The same low values of 2D:4D ratio have been associated with women with high waist-to-hip ratio, masculine and are more athletic (Csathó et al., 2003a; Manning et al., 2000; Pokrywka et al., 2005). A gender free role for $2 \mathrm{D}: 4 \mathrm{D}$ ratio in predicting psychological traits had also been reported in the literature. Verbal intelligence and agreeableness are positively correlated with 2D:4D ratio while numerical intelligence and physical fitness were negatively correlated with it (Hönekopp et al., 2006; Luxen and Buunk, 2005). Specifically, the negative correlations implies that a low 2D:4D correlated with numeric capabilities (Brosnan, 2006 and Brosnan et al., 2011). The association of digit ratios with psychological and physical triats appears to be explained by the underlying influence of the changes in the hemostatic balance of testestorone and estrogen on neuronal proliferation, migration, differentiation, and apoptosis (Zheng and Cohn, 2011; Mrazik and Dombrowski, 2010; Manning, 2002). The current study was aimed at evaluating the relationship between $2 \mathrm{D}: 4 \mathrm{D}$ ratio with academic performance among secondary school students in Gwale LGA, Kano, Nigeria.

\section{MATERIALS AND METHODS}

The subjects that participated in this study were students of Nasarawa secondary school of Gwale Local Government Area, Kano State, Nigeria. An introduction letter was obtained from Anatomy department of the Yusuf Maitama Sule University Kano, and an information sheet regarding the study design was presented to the management of the school for onward dissemination to parents. Only students whose parents gave a verbal consent for the study were recruited for the current study. A proforma for recording data was adapted with its relevant sections on socio-demography and measurements of interest (anthropometric and academic performance). Anthropometric measurements on participants were carried out by the researcher and aided by two well-trained assistants. The measurement carried out included measurements of the hand digit length using a digital venier caliper (Neiko) which has an accuracy of about $0.05 \mathrm{~mm}$. The measurement was carried out on the ventral surface of the hand from the basal crease of the digit to the tip of the digit and this approach was adapted from an earlier work (Manning et al., 1998, Danborno et al., 2010). This measurement approach has been reported to have high degree of repeatability and all measurements were made in duplicates and then the average values were recorded as the measurement value so as to increase the accuracy of the results (Manning et al., 1998). Assessment of the academic performance of the recruited students was carried out using the grades and / or scores the individual student earned during their terminal exams. The grades for the terminal exams were retrieved directly from the teachers of the students.

\section{RESULTS}

The measurements of digit length in males and females were carried out in the current study and the mean results were presented in Table 1 . The female digit measurements were lower than those of the males while the values for the 2D : $4 D$ ratio obtained in both the right and left hands were higher among females compared to males. The statistical evaluation of the level of difference in the individual digit measurement values obtained from females compared to males was observed to be statistically significant with $\mathrm{P} \leq 0.05$, whereas the difference in the values of the ratio were not significant (Table 1 ).

Table 1: The mean hand digit length of the secondary school student of Nasarawa school, Gwale, Kano state

\begin{tabular}{|c|c|c|c|}
\hline Digit measured & $\begin{array}{l}\text { Mean } \pm \text { SD } \\
\mathrm{N}=205\end{array}$ & $\begin{array}{l}\text { Mean } \pm \text { SD } \\
\text { (Males) } \\
\mathrm{n}=110\end{array}$ & $\begin{array}{c}\text { Mean } \pm \text { SD } \\
\text { (Females) } \\
n=95\end{array}$ \\
\hline Left 2D $(\mathrm{cm})$ & $61.160 \pm 6.730$ & $62.997 \pm 6.664 * *$ & $59.041 \pm 6.179 * *$ \\
\hline Left 4D $(\mathrm{cm})$ & $63.590 \pm 6.860$ & $65.556 \pm 6.649 * *$ & $61.311 \pm 6.417^{* *}$ \\
\hline Right 2D $(\mathrm{cm})$ & $61.350 \pm 6.710$ & $63.263 \pm 6.579 * *$ & $59.143 \pm 6.193 * *$ \\
\hline Right 4D (cm) & $63.610 \pm 6.920$ & $65.674 \pm 6.683 * *$ & $61.227 \pm 6.443 * *$ \\
\hline Right2D: 4D & $0.970 \pm 0.020$ & $0.963 \pm 0.018$ & $0.966 \pm 0.0232$ \\
\hline Left 2D:4D & $0.960 \pm 0.018$ & $0.961 \pm 0.015$ & $0.963 \pm 0.021$ \\
\hline 2D:4D ratio & $0.963 \pm 0.017$ & $0.962 \pm 0.144$ & $0.965 \pm 0.020$ \\
\hline
\end{tabular}


BAJOPAS Volume 13 Number 2, December, 2020

In the results obtained in the terminal test for the three (3) subjects evaluated, it was observed that the females obtained a higher score for each subject compared to their male counterparts and the difference in scores were statistically significant $(P \leq 0.05)$ (Table 2$)$.

Table 2 : The academic scores in a terminal exam among secondary school students of Nasarawa school, Gwale, Kano state

\begin{tabular}{llll}
\hline Subject & $\begin{array}{l}\text { Mean } \pm \mathrm{SD} \\
\mathrm{N}=205\end{array}$ & $\begin{array}{l}\text { Mean } \pm \mathrm{SD} \\
\text { (Males). } \mathrm{n}=110\end{array}$ & $\begin{array}{l}\text { Mean } \pm \mathrm{SD} \\
\text { (Females). } \mathrm{n}=95\end{array}$ \\
\hline Maths & $48.522 \pm 12.357$ & $47.390 \pm 12.446^{*}$ & $49.926 \pm 12.168^{*}$ \\
English & $50.951 \pm 9.665$ & $49.591 \pm 9.631^{*}$ & $52.526 \pm 9.512^{*}$ \\
Biology & $70.766 \pm 15.895$ & $65.918 \pm 15.078^{* *}$ & $76.400 \pm 15.003^{* *}$ \\
Cummlative & $56.749 \pm 10.459$ & $54.273 \pm 10.219^{* *}$ & $59.618 \pm 10.042^{* *}$ \\
assessment (CA) & & & \\
\hline
\end{tabular}

Statistical evaluation was done using the Mann-Whitney $U$ test for the difference in the scores obtained by males and female in each subject. $* \mathrm{p}$ value for the comparison between female and male score $\leq 0.05$ (Maths test, $\mathrm{P}=0.017$; English test, $\mathrm{P}=0.012$ ); $* * \mathrm{p}$ value for the comparison between female and male score $\leq 0.001$ (Biology test, $\mathrm{P}=0.000003$; Cummulative assessment, $\mathrm{P}=$ 0.000058).

In the evaluation of relationship between measurement of the digit sizes in the right and left hand, with scores of academic performance, only the scores for biology was significantly correlated with the digit dimensions, but it was not correlated with the 2D:4D ratio (Table 3 ).
Thus, the dimensions of the digit measurement of the second right, second left , fourth right and fourth left digits were significantly correlated with the scores in Biology only and the association was observed to be a negative correlation (Table 3).

Table 3: Correlations between digital anthropometric parameters with academic scores from terminal examination among secondary school students of Nasaraw school, Gwale, Kano state

\begin{tabular}{lllrrrr}
\hline & & & & \\
\hline Spearman's rho & & \multicolumn{1}{c}{$\mathrm{E}(\%)$} & $\mathrm{B}(\%)$ & \multicolumn{1}{c}{ CA } \\
& L2D & Correlation Coeff & .019 & -.069 & $-.166^{*}$ & -.102 \\
& & Sig. (2-tailed) & .784 & .328 & .018 & .145 \\
& L4D & Correlation Coeff & .030 & -.053 & $-.170^{*}$ & -.096 \\
& & Sig. (2-tailed) & .669 & .449 & .015 & .172 \\
& L2D/L4D & Correlation Coeff & -.049 & -.103 & .019 & -.043 \\
& Sig. (2-tailed) & .490 & .143 & .781 & .537 \\
& R2D & Correlation Coeff & .022 & -.080 & $-.185^{* *}$ & -.115 \\
& Sig. (2-tailed) & .749 & .254 & .008 & .100 \\
& R4D & Correlation Coeff & .018 & -.072 & $-.195^{* *}$ & -.121 \\
& Sig. (2-tailed) & .795 & .307 & .005 & .084 \\
& R2D/R4D & Correlation Coeff & .059 & -.020 & .063 & .049 \\
& Sig. (2-tailed) & .402 & .775 & .371 & .483 \\
& 2D : 4D & Correlation Coeff & .026 & -.070 & .050 & .015 \\
& Sig. (2-tailed) & .709 & .316 & .474 & .831 \\
& M(\%) & Correlation Coeff & 1.00 & $.628^{* *}$ & $.455^{* *}$ & $.809^{* *}$ \\
& Sig. (2-tailed) & & .000 & .000 & .000 \\
& E(\%) & Correlation Coeff & & 1.000 & $.497^{* *}$ & $.795^{* *}$ \\
& Sig. (2-tailed) & & & .000 & .000 \\
& B(\%) & Correlation Coeff & & & 1.000 & $.837^{* *}$ \\
CA & Correlation Coeff & & & & 1.000 \\
\hline
\end{tabular}

**. Correlation is significant at the 0.01 level (2-tailed); *. Correlation is significant at the 0.05 level (2-tailed). Coeff is coefficient, B is Biology, $E$ is English, M is Maths, 2D issecond digit, 4D is fourth digit, $L$ is Left $R$ is right.

The correlation between measurements of the R2D, L2D, R4D, and L4D with the scores in Maths, English, Biology and Cumulative average were found to be statistically significant and was positively correlated among males students (Table 4). However, none of the correlations between the academic scores (Maths, English, Biology and Cummulative average) with the 2D : $4 \mathrm{D}$ ratio of the right and left hands as well as the average of $2 D: 4 D$ ratio of both hands were statistically significant (Table 4). 
BAJOPAS Volume 13 Number 2, December, 2020

Table 4: Correlations between digital anthropometric parameters of digit with academic scores from termina examination among male secondary school students of Nasaraw school, Gwale, Kano state

\begin{tabular}{|c|c|c|c|c|c|c|}
\hline & & & $\mathrm{M}(\%)$ & $\mathrm{E}(\%)$ & $\mathrm{B}(\%)$ & $\mathrm{CA}$ \\
\hline \multirow[t]{21}{*}{ Spearman's rho } & L2D & Correlation Coeff. & $.276^{* *}$ & $.211^{*}$ & $.263^{* *}$ & $.283^{* *}$ \\
\hline & & Sig. (2-tailed) & .004 & .027 & .006 & .003 \\
\hline & L4D & Correlation Coeff & $.297^{* *}$ & $.226^{*}$ & $.271^{* *}$ & $.296^{* *}$ \\
\hline & & Sig. (2-tailed) & .002 & .017 & .004 & .002 \\
\hline & L2D/L4D & Correlation Coeff & -.076 & -.061 & .050 & -.001 \\
\hline & & Sig. (2-tailed) & .433 & .523 & .601 & .990 \\
\hline & R2D & Correlation Coeff & $.273^{* *}$ & $.191^{*}$ & $.244^{*}$ & $.267^{* *}$ \\
\hline & & Sig. (2-tailed) & .004 & .045 & .010 & .005 \\
\hline & R4D & Correlation Coeff & $.284^{* *}$ & $.197^{*}$ & $.229^{*}$ & $.259^{* *}$ \\
\hline & & Sig. (2-tailed) & .003 & .040 & .016 & .006 \\
\hline & R2D/R4D & Correlation Coeff & -.031 & -.004 & .120 & .065 \\
\hline & & Sig. (2-tailed) & .748 & .968 & .211 & .501 \\
\hline & $2 D: 4 D$ & Correlation Coeff & -.059 & -.037 & .097 & .041 \\
\hline & & Sig. (2-tailed) & .543 & .704 & .315 & .670 \\
\hline & $M(\%)$ & Correlation Coeff & 1.000 & $.617^{* *}$ & $.468^{* *}$ & $.801^{* *}$ \\
\hline & & Sig. (2-tailed) & . & .000 & .000 & .000 \\
\hline & $\mathrm{E}(\%)$ & Correlation Coeff & & 1.000 & $.526^{* *}$ & $.798^{* *}$ \\
\hline & & Sig. (2-tailed) & & . & .000 & .000 \\
\hline & $\mathrm{B}(\%)$ & Correlation Coeff & & & 1.000 & $.848^{* *}$ \\
\hline & & Sig. (2-tailed) & & & & .000 \\
\hline & CA & Correlation Coeff & & & & 1.000 \\
\hline
\end{tabular}

**. Correlation is significant at the 0.01 level (2-tailed); *. Correlation is significant at the 0.05 level (2-tailed). Coeff is coefficient, B is Biology, $E$ is English, $M$ is Maths, 2D issecond digit, $4 D$ is fourth digit, $L$ is Left R is right.

The correlation between measurements of the R2D, L2D, R4D and L4D with the scores of academic performance (in all the subjects, except Maths) among females were statistically significant. However, the result for the correlation between the academic performance scores (Maths, English, Biology and Cummulative average) with the 2D:4D ratio of the right and left hands was not statistically significant (Table 5).

Table 5: Correlations between digital anthropometric parameters with academic scores from a terminal examination among secondary school female students of Nasarawa school, Gwale, Kano state

\begin{tabular}{|c|c|c|c|c|c|c|}
\hline & & & $M(\%)$ & $E(\%)$ & $\mathrm{B}(\%)$ & $\mathrm{CA}$ \\
\hline \multirow[t]{14}{*}{ Spearman's ho } & L2D & Correlation Coeff & -.177 & $-.265^{* *}$ & $-.450^{* *}$ & $-.387^{* *}$ \\
\hline & & Sig. (2-tailed) & .086 & .010 & .000 & .000 \\
\hline & L4D & Correlation Coeff & -.187 & $-.240^{*}$ & $-.461^{* *}$ & $-.387^{* *}$ \\
\hline & & Sig. (2-tailed) & .070 & .019 & .000 & .000 \\
\hline & L2D/L4D & Correlation Coeff & -.037 & -.162 & -.010 & -.105 \\
\hline & & Sig. (2-tailed) & .719 & .116 & .924 & .312 \\
\hline & R2D & Correlation Coeff & -.177 & $-.275^{* *}$ & $-.472^{* *}$ & $-.403^{* *}$ \\
\hline & & Sig. (2-tailed) & .087 & .007 & .000 & .000 \\
\hline & R4D & Correlation Coeff & -.196 & $-.252^{*}$ & $-.488^{* *}$ & $-.413^{* *}$ \\
\hline & & Sig. (2-tailed) & .056 & .014 & .000 & .000 \\
\hline & R2D/R4D & Correlation Coeff & .168 & -.052 & .017 & .062 \\
\hline & & Sig. (2-tailed) & .103 & .618 & .867 & .548 \\
\hline & $2 D: 4 D$ & Correlation Coeff & .112 & -.108 & .020 & .008 \\
\hline & & Sig. (2-tailed) & .281 & .296 & .847 & .936 \\
\hline
\end{tabular}

**. Correlation is significant at the 0.01 level (2-tailed); *. Correlation is significant at the 0.05 level (2-tailed). Coeff is coefficient, $B$ is Biology, $E$ is English, $M$ is Maths, $2 D$ issecond digit, $4 D$ is fourth digit, $L$ is Left $R$ is right. 
BAJOPAS Volume 13 Number 2, December, 2020 DISCUSSION

The results from this study suggested that there were correlations between second digit length of the right hand and that of the left hand with the digit measurements of the right and left fouth digit irrespective of gender. In addition, the second digit length was correlated with the $2 \mathrm{D}$ : $4 \mathrm{D}$ ratio of the left hand and that of the average value from the 2D : 4D ratio of both hands. The correlation between the size of the fourth left digit with the size of the right and left second digit as well as the left second digit and the 2D : $4 D$ ratio of the left hand when the entire population was analysed was observed. In males, the same result of correlation was observed for the left fourth digit except that the association with the right $2 \mathrm{D}: 4 \mathrm{D}$ ratio and the that of the average from the 2D : 4D ratio of both hands was not significant. In females all assessment between $L 4 D$ with all the three forms of 2D:4D ratio in this study were not significant. The evaluation in male students and entire study population for the relationship between the size of the right fourth digit (R4D) and all the other digit in this study were significantly correlated, except for the 2D:4D ratio from the right hand and the average $2 D$ : $4 \mathrm{D}$ ratio from both hands. The same result was observed when the evaluations was carried out among the female students except that all the three different formats of the 2D:4D ratios in the study were not significantly correlated with the size of R4D.

In the entire population, only the scores for biology were negatively correlated with the digit dimensions. In males students, all the individual and cumulative average scores from Maths, English and Biology were positively correlated with the digit sizes while in females, only Biology, English and Cummulative average scores were negatively correlated with the size of the digits measured in the study. It is pertinent to note that none of the three different forms of 2D : 4D ratio (R2D : 4D; L2D : 4D and 2D : 4D) was significantly correlated with any of the examination scores in this study.

The significantly higher measurements for 2D : $4 D$ values among female compared to males in the current study was in keeping with earlier reports in the literature (Tektas et al., 2019).

\section{REFERENCES}

Bailey, A. A. and Hurd, P. L. (2005). Finger length ratio correlates with Physical 92 aggression in men but not in women. Biological Psychology, 68; 215- 222.

Brañas-Garza $P$, Kovárík J, Neyse L (2013) Second-to-fourth digit ratio has a non-monotonic impact on altruism. PLOS
Similarly, in the current study there was no correlation between digit ratio and academic performance including performance in Math, and this observation was in tandem with an earlier finding in the literature (Tektas et al., 2019). There were literature reports that revealed an association between academic performance and digit ratio and thus these reports were in contrast to the current finding (Brosnan, 2011; Brosnan, 2006). The current finding was also in contrast with an earlier report of a significant correlation between 2D:4D and success in admission tests for a school in Italy (Coco et al., 2011). There are literature reports that suggest that high prenatal level of testosterone may be associated with better performance in numerical abilities among Boys and Men (Tektas et al., 2019; Mrazik and Dombrowski, 2010; Fink, 2006). The biological basis for the effect of prenatal testosterone on intelligence is hinged on the fact that it influences neuronal proliferation, migration, differentiation, and apoptosis. Specifically, it promotes the development and organization of dense neuronal networks in areas related to cognition, learning and memory, either by decreasing apoptosis of brain cells during development, or increasing migration of cells to one of those areas (Lenz et al., 2012; Mrazik and Dombrowski, 2010). Nevertheless, the females in the current study performed better in all the subjects evaluated including Maths. The inconsistencies in the association between digit sizes, digit ratio and academic performance in this study is in keeping with such findings in earlier studies (Galizzi and Nieboer, 2015, Brañas-Garca et al. 2013). These inconsistences may be because the regulation of these features are not dependent on testestorone and estrogen levels only, but other factors such as prenatal corticosterone and genetic factors that have also been implicated in the determination of academic performance (Warrington et al., 2018; Lilley et al., 2010).

\section{CONCLUSION}

Lower 2D:4D ratio were observed among the male students and the digit ratio were not correlated with the academic performance of both male and female students, including their performance in Maths.

ONE 8:

e60419

10.1371/journal.pone.0060419

[doi];PONE-D-12-32101 [pii]

Breedlove S. M. (2017). Prenatal Influences on Human Sexual Orientation: Expectations versus Data. Archives of sexual behavior, 46(6), 1583-1592. 
BAJOPAS Volume 13 Number 2, December, 2020 https://doi.org/10.1007/s10508-0160904-2

Brosnan, M. J. (2006). Digit ratio and faculty membership: Implications for the relationship between prenatal testosterone and academia. British Journal of Psychology, 97; 455-466.

Brosnan, M., Gallop, V., Iftikhar, N., \& Keogh, E. (2011). Digit ratio (2D:4D), academic performance in computer science and computer-related anxiety. Personality and Individual Differences, 51(4), 371375. https://doi.org/10.1016/j.paid.2010 .07 .009

Brown, W. M., Finn, C. J., Cooke, B. M. and Breedlove, S. M. (2002). Differences in finger length ratios between selfidentified "I, butch ${ }^{\prime \prime \prime}$ and ${ }^{\prime \prime \prime \prime}$ femme ${ }^{\prime \prime \prime}$ lesbians. Archives of Sexual Behavior, 31; 123-127.

Burley, N. T. and Foster, V. S. (2004) Digit ratio varies with sex, egg order, and strength of mate preference in zebra finches. Proceedings of the Royal Soceity 271; 239-244.

Coco, M., Perciavalle, V., Maci, T., Nicoletti, F., Di Corrado, D. and Perciavalle, V. (2011). The second-to-fourth digit ratio correlates with the rate of academic performance in medical school students. Molecular Medicine, 4; 471-476.

Csatho, A., Osvath, A., Bicsack, E., Karadi, K., Manning, J. and Kallai, J. (2003). Sex role identity related to the ratio of second to fourth digit length in women. Biological Psychology, 62; 147-156.

Danborno, B., Adebisi, S. S., Adelaiye, A. B. and Ojo, S. A. (2007). Relationship between second and fourth digit lengths, digit ratio (2D:4D) and aggression in Nigerians. Journal of Environmental Neuroscience Biomedicine, 2(1); 229234.

Danborno, B., Adebisi, S. S., Adelaiye, A. B. and Ojo, S. A. (2010). Relationship between digit ratio (2D:4D) and birth weight in Nigerians. Anthropologist 12(2); 127130.

Fink B, Thanzami V, Seydel, H. and Manning J. T. (2006). Digit ratio and hand grip strength in German and Mizos men: cross-cultural evidence for an organising effect of prenatal testosterone on strength. American Journal of Human Biology 18:776-782.

Galizzi MM, Nieboer J (2015) Digit ratio (2D:4D) and altruism: evidence from a large, multi-ethnic sample. Front Behav
Neurosci 9:

10.3389/fnbeh.2015.00041

Hönekopp, J., Voracek, M. and Manning, J. T. (2006). 2nd to 4th digit ratio (2D:4D) and number of sex partners: Evidence for effects of prenatal testosterone in men. Psychoneuroendocrinology, 3;3037.

Klimek, M., Galbarczyk, A., Nenko, I., Alvarado, L. C., \& Jasienska, G. (2014). Digit ratio (2D:4D) as an indicator of body size, testosterone concentration and number of children in human males. Annals of human biology, 41(6), 518-523. https://doi.org/10.3109/03014460.2014. 902993

Lenz B, Müller CP, Stoessel C, Sperling W, Biermann T et al. (2012) Sex hormone activity in alcohol addiction: Integrating organizational and activational effects. Prog Neurobiol 96: 136-163 10.1016/j.pneurobio.2011.11.001

Lilley $\mathrm{T}$, Laaksonen $\mathrm{T}$, Huitu $\mathrm{O}$, Helle $\mathrm{S}$ (2010) Maternal corticosterone but not testosterone level is associated with the ratio of second-to-fourth digit length (2D:4D) in field vole offspring (Microtus agrestis). Physiol Behav 99: 433-437. S0031-9384(09)00375-8 [pii]; 10.1016/j.physbeh.2009.11.015

Luxen, M. F. and Buunk, B. P. (2005). Secondto-fourth digit ratio related to Verbal and Numerical Intelligence and the Big Five. Personality and Individual Differences, 39;959-966.

Malas, A. M., Dogan, S., Evcil, E. H. and Desdicioglu, K. (2005). Fetal development of the hand, digit, and digit ratio (2D:4D). Early Human Development, 10-101.

Manning, J. T., Scott, D., Wilson, J. and LewisJones, D. I. (1998). The ratio of $2^{\text {nd }}$ to $4^{\text {th }}$ digit length: a predictor of sperm numbers and concentratio of testosterone, leutenizing hormone and oestrogen. Human Reproduction, 1311; 3000-3004.

Manning, J. T. and Taylor, R. P. (2001). Second to fourth digit ratio and male ability in sport: implications for sexual selection in humans. Evolution and Human Behavior, 22; 61-69.

Manning, J. T. (2002). Digit ratio: $A$ pointer to fertility, behavior, and health. New Brunswick: Rutgers University Press.

McIntyre, M. H., Ellison, F. T., Lieberman, D. E., Demerath, E. and Towne, B. (2005). The development of sex differences in digital formula from infancy in the Fels 
BAJOPAS Volume 13 Number 2, December, 2020 longitudinal study. Proceedings Royal Society, 272; 1473-1479.

Mrazik, M. and Dombrowski, S. C. (2010). The neurobiological foundations of giftedness. Roeper Review, 32; 224-234

Pokrywka, L., Rachon, D., Suchecka-Rachon, K. and Bitel, L. (2005). The second to fourth digit ratio in elite and non-elite female athletes. American Journal of Human Biology, 17;796-800.

Rahman, Q. and Wilson, G. D. (2003). Sexual orientation and the 2nd to 4th finger length ratio: evidence for organizing effects of sex hormones or developmental instability? Psychoneuroendocrinology, 28; 288303.

Rammsayer, T. H. and Troche, S. J. (2007). Sexual dimorphism in second-to-fourth digit ratio and its relation to gender-role orientation in males and females. Personality and IndividualDifferences, 42; 911-920.

Robinson, S. J. and Manning, J. T. (2000). The ratio of 2nd to 4th digit length and male homosexuality. Evolution and Human Behavior, 21; 333-345.

Tektas O Y., Kapsner L., Lemmer M., BounaPyrrou P., Lenz B., Kornhuber J., Voracek M (2019). Digit ratio (2D:4D) and academic success as measured by achievement in the academic degree "Habilitation" PLOS One. 2019; 14(2): e0212167.

doi: 10.1371/journal.pone.0212167

Trivers, R., Manning, J. T. and Jacobson, A. (2006). A longitudinal study of digit ratio (2D:4D) and other finger ratios in Jamaican children. Hormones and Behavior, 49; 150-156.

Warrington NM, Shevroja E, Hemani G, Hysi PG, Jiang $Y$ et al. (2018) Genome-wide association study identifies nine novel loci for 2D:4D finger ratio, a putative retrospective biomarker of testosterone exposure in utero. Hum Mol Genet 27: 2025-2038. 4969373 [pii]; $10.1093 / \mathrm{hmg} / \mathrm{ddy} 121$

Williams, J. H. G., Greenhalgh, K. D. and Manning, J. T. (2003). Second to fourth finger ratio and possible precursors of developmental psychopathology in preschool children. Early Human Development, 72; 57-65.

Zheng, Z. and Cohn, M. J. (2011). Developmental basis of sexually dimorphic digit ratios. Proceedings of the National Academy of Sciences USA, 108; 16289- 16294. 